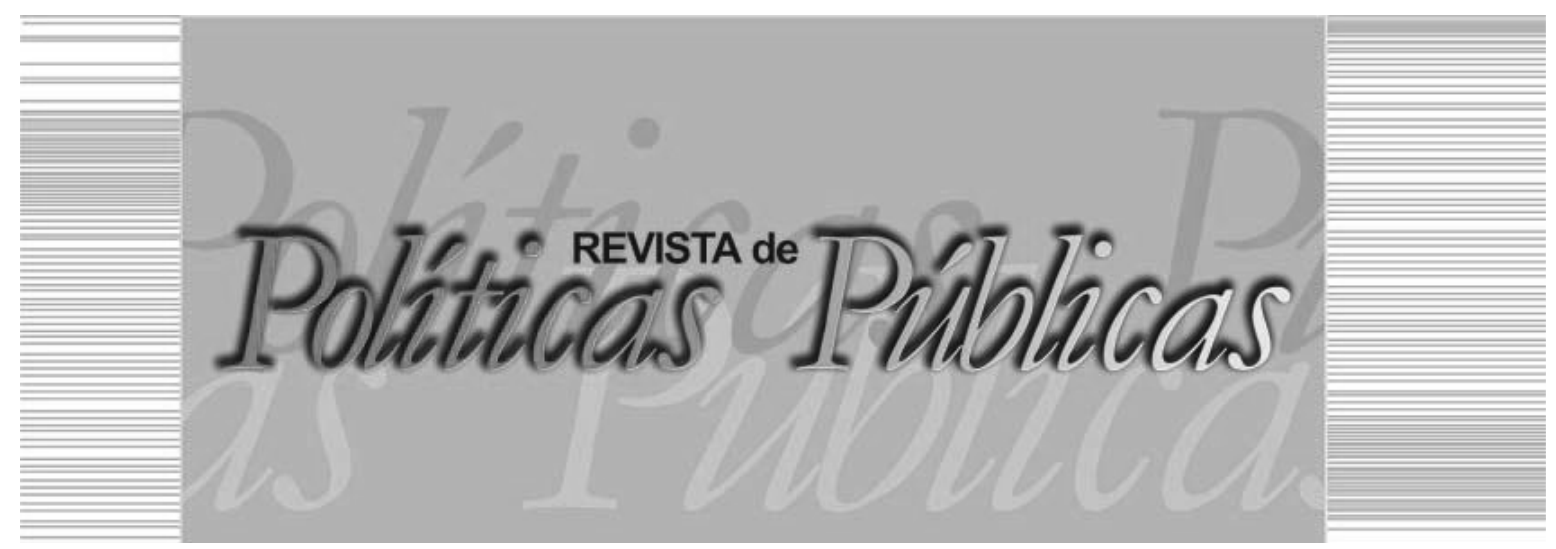

\title{
POLITICA CULTURAL EM TEMPO DE CRISE: O Ministério da Cultura no Governo Temer
}

\section{Alexandre Barbalho ${ }^{1}$}

\section{Resumo}

O presente artigo se insere no esforço mais amplo de análise da crise da política cultural brasileira que se inicia desde a gestão Ana de Hollanda no Ministério da Cultura. No recorte proposto para este trabalho, se investiga o desdobramento desse fenômeno no governo Temer, na gestão do ministro Sergio Sá Leitão. Como aporte teórico-metodológico, recorre-se aos conceitos de campo e Estado em Pierre Bourdieu. Como conclusão, constata-se a conformação da política cultural à política de reforma neoliberal em curso no atual governo.

Palavras-chave: Política cultural, crise, neoliberalismo

\section{CULTURAL POLICY IN TIME OF CRISIS:the Ministry of Culture in the Temer government}

\begin{abstract}
This article is part of the broader effort to analyze the crisis of Brazilian cultural policy that has been underway since the Ana de Hollanda administration in the Ministry of Culture. In the proposed clipping for this work, one investigates the unfolding of this phenomenon in the Temer government, in the administration of the minister Sergio Sá Leitão. As a theoretical-methodological contribution, the concepts of field and state in Pierre Bourdieu are used. As a conclusion, it's visible the conformation of cultural policy to the policy of neoliberal reform underway in the current government.

Key words: Cultural policy, crisis, neoliberalism.

\footnotetext{
Graduado em História e em Ciências Sociais, Doutor em Comunicação e Cultura Contemporâneas, Professor dos Programas de Pós-Graduação em Sociologia e em Políticas Públicas da Universidade Estadual do Ceará (UECE). E-mail: alexandrealmeidabarbalho@gmail.com / Endereço: Universidade Estadual do Ceará - UECE: Av. Dr. Silas Munguba, 1700 - Campus do Itaperi, Fortaleza. CE, 60741-000
} 


\section{INTRODUÇ̃̃O}

O governo Temer, diante da crise política generalizada, procura estruturar-se, entre outro meios, pela implementação de uma pauta reformista de viés liberal, em vez de criar condições para um papel mais ativo do Estado. Trata-se, portanto, de outro projeto político que se contrapõe àquele vigente nos governos Lula e Dilma pautado pelo neodesenvolvimentismo com participação estatal.

Outro recurso do atual governo para demarcar seu projeto em relação ao imediatamente anterior é o da não valorização e consequente enfraquecimento das instâncias participativas de políticas públicas. É sintomático que no III Encontro Internacional Participação, Democracia e Políticas Públicas, realizado em meados de 2017 na Universidade Federal do Espírito Santo (UFES), Vitória, se debatesse questões relativas aos desafios à participação na conjuntura do pós-impedimento, bem como os limites que o momento político impunha às instituições participativas e os efeitos desses constrangimentos.

O embate entre os dois projetos políticos diferenciados (governos petistas e governo Temer) e sua relação com a cultura, tema deste artigo, remete à discussão de Evelina Dagnino em relação às três dimensões principais de uma nova cidadania que emerge após o Regime Militar. A primeira destas dimensões é a sua ligação concreta com os movimentos sociais e suas lutas por direitos coletivos. A segunda, a experiência e a prática de tais movimentos na construção da democracia e, ao mesmo tempo, de sua ampliação e aprofundamento.

Por fim, o nexo constitutivo entre a cultura e a política ao reivindicar determinadas características da sociedade contemporânea, como o papel da subjetividade e a consequente emergência de novos sujeitos e direitos sociais. Ampliando o espaço do político, a terceira dimensão da nova cidadania estrategicamente "[...] reconhece e enfatiza o caráter intrínseco e constitutivo da transformação cultural para a construção democrática." (DAGNINO, 1994, p. 104).

Contudo, o fortalecimento do projeto liberal ao longo dos anos 1990 favoreceu ao estabelecimento daquilo que Dagnino (2005) denomina de confluência perversa entre dois projetos políticos: o democrático e aquele defendido pelo neoliberalismo. O primeiro investe na ampliação da democracia com a constituição de 
novos espaços públicos e a participação da sociedade civil na definição, execução e controle das políticas públicas. O segundo defende o Estado mínimo, não apenas no setor produtivo, mas inclusive na promoção de direitos coletivos, nas responsabilidades sociais e na transparência de suas ações. Apesar dos meios e dos fins de ambos os projetos serem distintos e até antagônicos, o projeto neoliberal escamoteia seu ideário ao apropriar-se e re-significar alguns ideais democráticos, mais especificamente as noções de sociedade civil, de participação e de cidadania.

Este contexto impregna inclusive as políticas culturais, e o desafio que se coloca à sua elaboração é justamente o de confrontar os dois projetos políticos, deixando claro suas distinções, diferenças e conflitos. A exposição do conflito demonstra exatamente o que está em jogo: "[...] uma disputa político-cultural entre distintos desenhos de sociedade e os respectivos setores sociais neles empenhados." (DAGNINO, 2005, p. 61 - itálico meu).

Contudo, em artigo recente, Dagnino (2016) observa como o neodesenvolvimentismo, implementado pelos governos Lula e Dilma, e avaliado como alternativa poderosa ao projeto neoliberal, não conseguiu romper com a lógica centralizadora própria ao Estado forte e protagonista do velho desenvolvimentismo, o que limitou as experiências participativas nestes governos. Isto resultou em mudanças na própria concepção de participação, que perdeu o sentido de compartilhamento de poder e assumiu o formato mais consultivo e dialógico, aproximando-se dos procedimentos neoliberais.

Nesse contexto é que se situa o projeto do governo Temer, elaborado inicialmente no manifesto Uma ponte para o futuro de outubro de 2015 e depois mais sistematizado no documento A travessia social, já em 2016, ambos produzidos e publicizados pela fundação Ulysses Guimarães do PMDB (FUNDAÇÃO ULYSSES GUIMARÃES, 2105, 2016). Nestes documentos, vale salientar, a cultura e as políticas culturais não são contempladas em momento algum - o que, longe de significar o resguardo da área das políticas liberais e reformistas, sinaliza o desconhecimento ou o não reconhecimento de seu papel estratégico para o país.

Contudo, esse processo não se dá sem resistência por parte de partidos e políticos da oposição, bem como por amplos setores da sociedade civil. O caso da cultura é emblemático da atual polarização e da disputa de projetos políticos distintos, pois remonta ainda 
ao primeiro governo Dilma, com a gestão de Ana de Hollanda no Ministério da Cultura (MinC), e atinge seu ponto mais crítico quando o governo interino de Temer decide extinguir o MinC. Em ambos os momentos, com distintos valores em disputa, ocorre uma forte reação do campo cultural que se encontra politizado pelo processo participativo implantado e fomentado pelo Ministério desde a gestão de Gilberto Gil (2003-2008) a partir de parâmetros estabelecidos pelos governos Lula, que tinham na participação popular um de seus valores fundantes (MARTINS, 2003), ainda que, como vimos acima, sofrendo mudanças no seu significado.

Por politização, me refiro ao fortalecimento de valores próprios ao campo político (representação, participação, deliberação, produção ideológica etc.) no campo cultural e que passam a guiar as disposições e tomadas de posição de seus agentes. Certamente, não se trata de momento único na história do país, como revela, por exemplo, a forte ligação entre política e cultura nos anos 1960. Contudo, o que diferencia o momento em análise é que se trata de uma politização do campo cultural em estreita conexão com a atuação da política federal de cultura, em seu desdobramento nos âmbitos estadual e municipal, em um período democrático. Este é o elemento novo: a conjunção de democracia e de presença do Estado na cultura por meio de políticas públicas, conjunção esta ausente nos governos anteriores (Collor/Itamar e Fernando Henrique Cardoso), posto que abdicaram, em grande parte, do papel do governo na condução de tais políticas, delegando-as para o jogo do mercado, via leis de incentivo (CASTELLO, 2002; MENDES, 2015).

Não é o caso aqui, por falta de espaço, de identificar e desenvolver todo o conjunto de políticas implementadas pelo MinC nos governos Lula e Dilma, mas faz-se necessário pontuar aquelas que mais favoreceram ao que estou denominando de politização, que são exatamente as que visaram a institucionalização das políticas culturais. Assim, a realização de três Conferências Nacionais de Cultura (CNC), da elaboração do Plano Nacional de Cultura (PNC), a implantação do Sistema Nacional de Cultural (SNC), a instalação do Conselho Nacional de Política Cultura (CNPC) e o Programa Cultura Viva ocupam uma posição central na constituição de uma nova doxa para o campo cultural. Isso porque as CNCs, o PNC, o SNC e o CNPC exigiram, para se efetivar, a participação de milhares de agentes em todas as regiões e estados e em grande parte dos municípios brasileiros. Já o Programa Cultura Viva, por meio de suas ações, em 
especial a dos Pontos de Cultura, implica na associação colaborativa do poder público com os movimentos e instituições culturais existentes na sociedade. (SOTO et al, 2010; REIS, 2010; LACERDA; MARQUES; ROCHA, 2010).

Esse processo crescente de envolvimento de agentes, não apenas do campo cultural, mas também de outros campos, bem como de diversos setores da sociedade historicamente exclú́dos dos processos decisórios - e em especial na cultura, que, ao contrário de outros setores mais bem estabelecidos no âmbito das políticas públicas, como a saúde e a educação, não dispunha até então de conferências, câmaras setoriais, conselhos deliberativos, entre outros instrumentos de democracia direta e/ou deliberativa -, na definição das políticas públicas levou-os a se tornarem também agentes político-culturais.

Partindo do pressuposto de que o momento de crise é privilegiado para análise do campo cultural brasileiro, o que se propõe neste artigo é investigar o desdobramento desse fenômeno no governo Temer. A primeira hipótese é que diante de um campo politizado o presidente acaba por não ceder o MinC a acordos políticos e encontra no atual ministro, Sérgio Sá Leitão, um agente que procura articular as pautas do campo cultural, com a agenda reformista do governo. A segunda hipótese, relacionada à primeira, é a de que esta articulação não provoca uma mudança radical na agenda cultural, mas o fortalecimento da dimensão econômica da cultura por ser mais adequada à lógica reformista-liberal vigente no atual governo.

Para tanto, o artigo se divide em quatro partes, seguidas das considerações finais. Na primeira, desenvolvo os conceitos de campo e Estado em Bourdieu que fundamentam a elaboração das hipóteses. Em seguida, analiso o início da crise na política pública de cultura durante a gestão de Ana de Hollanda (2011-2012) no MinC e seu acirramento com o governo interino. Na quarta seção, avalio a possível conformação do Ministério à proposta política em curso no país.

\section{CAMPO CULTURAL, ESTADO E CRISE POLÍTICA}

Para compreender como se dão as disputas em torno das políticas culturais nos governos Dilma e Temer, é preciso levar em consideração não apenas os agentes, seus respectivos interesses e investimentos de capital no campo cultural (BOURDIEU, 1989, 1992), mas também perceber suas inter-relações com o Estado - entendido 
este como uma espécie de meta-campo, para onde convergem todos os tipos de capital, que por sua vez gera um meta-capital, "[...] un capital qui a la propriété particulière d'execer du pouvoir sur le capital." (BOURDIEU, 2012, p. 311). O Estado, portanto, é "meta", um poder acima dos outros poderes.

O Estado, continua Bourdieu (2012, p. 15), “[...] fonde l'intégracion logique et l'intégracion morale du monde social et, par là, le consensus fondamental sur le sens du monde social qui est la condition même des conflits à propôs du monde social". Ou seja, lugar da integração, o Estado é o fiador dos conflitos sociais, dos dissensos, incluso daqueles de base cultural.

Nesse sentido, o Estado não pode ser entendido como um bloco monolítico. Na medida em que detém meta-capital, "[....] est un champ à l'intérieur duquel les agentes luttent pour posséder un capital qui donne pouvoir sur les autres champs." (BOURDIEU, 2012, p. 312). O laço entre o campo do poder e o Estado se dá pelo fato de os agentes do primeiro disputarem o controle sobre o segundo, sobre seu meta-capital que permite conservar e reproduzir diferentes tipos de capital. Assim, tal como os outros campos, o Estado se estrutura a partir de oposições e interesses diferentes associados, inclusive, a capitais distintos, para impor o ponto de vista dos pontos de vista, que é o estatal.

A relação do campo estatal com o campo cultural, inserido na sociedade civil, se dá por meio das políticas governamentais de cultura, posto que, como defende Bourdieu (2012, p. 66), entre ambos, campo estatal/campo cultural, ou dito de outra forma, Estado/ sociedade civil (mais especificamente intelectuais e artistas, ou seja, os agentes culturais) existe um continuum, "une distribution continue de l'accès aux ressources collectives, publiques, matérielles ou symboliques, auxquelles on associe le nom d'État". O controle de tal distribuição, como toda aquela que se dá no socius, fundamenta e ocasiona lutas permanentes no interior dos campos estatal e cultural.

O Estado, portanto, se apresenta como "[...] une sorte de réserve de ressources symboliques, de capital symbolique, qui est à la fois un instrument pour un certain type d'agents et l'enjeu de luttes entre ces agentes." (BOURDIEU, 2012, p. 110); como um processo de concentração de recursos e de disputa por monopolizar esses recursos. Um momento de crise política, portanto, é aquele de acirramento dessas lutas em torno desse poder simbólico, onde cada agen- 
te, individual e/ou coletivo, reivindica para si o poder de nomeação, que é próprio ao Estado ${ }^{1}$.

Por sua vez, pensando na especificidade do objeto de análise, ou seja, a crise no Ministério da Cultura e de suas políticas, faz-se necessário levar em consideração exatamente esse dado: é preciso observar a estrutura de espaço onde se desenvolveram tais políticas; suas particularidades, as propriedades de seus agentes, as interseções dos campos nas quais se constroem (campo estatal, campo cultural, mas também campo midiático).

3 NA CULTURA, A CRISE VEM DE ANTES: a gestão Ana de Hollanda

Como já foi dito, os governos Lula imprimiram um novo patamar nas relações entre o governo federal e a cultura, ampliando e, principalmente, transformando a atuação do $\mathrm{MinC}$, sob a gestão dos ministros Gilberto Gil e Juca Ferreira (2008-2010). Este projeto se revela, por exemplo, na reestruturação do Ministério e do Conselho Nacional de Cultura, na realização das conferências nacionais, estaduais e municipais de cultura, na elaboração do Plano Nacional e na implantação do Sistema Nacional de Cultura, entre outros programas e ações que visam superar a descontinuidade das políticas culturais, transformando-as, minimamente, em políticas de Estado. (BARBALHO; RUBIM, 2015; RUBIM, 2010; 2011).

No entanto, o primeiro governo Dilma (2011-2014), ainda que representando uma continuidade do projeto político capitaneado pelo PT, trouxe mudanças significativas no que se refere às políticas culturais. Não cedendo à pressão de vários setores, inclusive de seu próprio partido, pela permanência de Juca Ferreira no Ministério, a presidenta nomeou, em janeiro de 2011, a artista Ana de Hollanda como ministra da Cultura. Reconfigurando a composição das forças políticas no interior do MinC, propondo novas pautas, dando continuidade a programas anteriores e enfraquecendo ou mesmo extinguindo outros, Hollanda provocou um forte movimento de oposição, inclusive interna, à sua gestão, o que terminou por afastá-la do cargo em setembro de 2012.

Para Doug McAdam, Sidney Tarrow e Charles Tilly (2009, p. 11-12), o confronto politico, que "[...] depende da mobilização, da criação de meios e de capacidades para a interação coletiva", se inicia quando "[...] as pessoas fazem reivindicações a outras pessoas 
cujos interesses seriam afetados se elas fossem atendidas". Ora, o que se observa entre 2011 e 2012 é um acúmulo de mobilizações e confrontos no e em torno do MinC, relativos a interesses distintos e que se estendem para além do campo cultural, envolvendo outros agentes e reverberando fortemente na mídia nacional e nas redes sociais. Em outras palavras, a gestão Ana de Hollanda configurou-se como uma situação-limite que resultou em rupturas.

Como observa Pasquino (2000), é, em geral, o nível da relação entre governo e sociedade o elemento determinante da crise do primeiro, o que resulta da sua falta de representatividade e de sua legitimidade, posto que é rejeitado por fortes setores sociais; e da ineficácia em responder a esse contexto de perda, levando ao imobilismo. A ministra gerou um déficit de representatividade e legitimidade, ao contrário do que ocorreu nas gestões anteriores, e não teve a capacidade de dar respostas eficazes, gerando uma insatisfação que se generalizou, configurando-se, portanto, como uma "crise governamental", uma vez que, restrita a um setor, foi sentida em outros subcampos do Estado.

Em outras palavras, ainda que detentora de meta-capital e do poder de nomeação, a ministra não soube avaliar o que estava em jogo e as disputas internas ao Estado e ao campo cultural e suas relações daí decorrentes. Dessa forma, não pôde exercer o papel de mediadora dos dissensos. Pelo contrário, suas jogadas só fizeram acirrar os conflitos e as mobilizações de oposição, muitas vezes tornando adversários certos agentes que, em um primeiro momento, não possuíam tal posição. (BARBALHO, 2017a).

4 O ACIRRAMENTO DA CRISE: o governo interino e a cultura

Quatro anos depois, ocorre a crise provocada com a extinção e a recriação do MinC pelo governo interino de Michel Temer - crise esta inserida naquela mais ampla que engloba todo o campo político brasileiro, pelo menos desde o início do segundo governo Dilma. (MELO, 2016).

De acordo com hipótese desenvolvida em outro artigo (BARBALHO, 2017b), o presidente interino recuou da decisão de extinguir o Ministério por conta do fortalecimento do campo cultural, com a maior presença das políticas federais a partir da gestão Gil, acompanhado de sua politização - fenômeno exposto na parte intro- 
dutória desse texto. Temer acabou cedendo aos diversos movimentos e mobilizações e anunciou, por meio do ministro da Educação Mendonça Filho, pasta que iria absorver o setor cultural, a recriação do MinC. De acordo com o depoimento do ministro, tratou-se de um "[...] gesto do presidente Temer no sentido de serenar os ânimos", uma vez que o Ministério teria sido recriado por seu caráter emblemático e pelas reações contrárias à sua extinção. (CRUZ, COLON; BRISOLLA, 2016; BRAGA, 2016).

Acontece que, ao contrário do que era esperado pelo governo interino, o retorno do MinC e a nomeação de Marcelo Calero provocaram o acirramento das posições dos agentes. Entre os grupos que ocupavam os prédios públicos nas capitais brasileiras, a medida não influiu na ocupação, pois o motivo também era se opor e resistir ao governo avaliado como ilegítimo. Essa foi uma posição generalizada nas ocupações. Além disso, as primeiras indicações do ministro foram recebidas com críticas.

Entre os artistas mais consagrados, ou entre as instituições que lhe representavam, porém, não havia a mesma unidade em torno da pauta Fora Temer. Enquanto alguns negavam a legitimidade do governo interino (MARIETA..., 2016), outros sinalizavam que, uma vez recriado o MinC, era hora de negociar com o novo Ministro. Para estes, independente de ser oposição ou não ao governo, o contexto era de retomada das políticas culturais.

Um dos argumentos principais utilizados em defesa do diálogo era o papel econômico da cultura e a necessidade de funcionamento dos instrumentos públicos voltados à sua promoção.

O movimento agora autodenominado Ocupa MinC (em clara referência ao Ocuppy) reagiu de forma contrária aos artistas e, principalmente, entidades que retomaram os canais de ligação com o Ministério, lançando nota onde afirmava sua posição de resistência e qualificava a iniciativa de oportunista e corporativista. (FRANCO, 2016).

A análise de Francisco Bosco, ex-presidente da Funarte na gestão Dilma, é elucidativa do grupo alinhado em torno do Ocupa MinC: "Há um esforço por parte desses produtores e artistas que estão legitimando o [ministro da Cultura] Calero de isolar a cultura do resto da sociedade brasileira". Os setores que passaram a apoiar Calero, segundo Bosco, não se importariam com um "[...] ministério 
de orientação liberal porque vão saber fazer pressão e ganhar os dividendos. Não é à toa que são, também, os que são contra a reforma da lei Rouanet." (SOARES, 2016, grifo nosso).

O momento de crise pelo qual passou o MinC durante o chamado governo interino é fecunda ao possibilitar o acesso aos posicionamentos de diversos agentes do campo cultural brasileiro e fora dele, bem como os valores que motivaram tais posições. A par da pluralidade das tomadas de posição (a favor ou contra o MinC; contra ou a favor de Temer; a favor ou contra a volta de Dilma), constatou-se como o debate foi politizado, a ponto de ser uma fala recorrente entre os que se opunham ao impedimento da presidenta a de que a cultura era o locus privilegiado, e talvez o mais visível, de resistência àquele processo político.

A partir das considerações desenvolvidas acima pode-se conjecturar que o contexto atual, pós-impedimento, seja resultado da tentativa de desmobilização dos agentes por parte do governo. Assim se entende o discurso assumido por dois ministros da Cultura do presidente Temer [Calero e Freire], bem como por outros setores de seu governo e do poder Legislativo, com ampla ressonância midiática, de que o MinC teria sido aparelhado pelo PT - discurso esse que reduz toda a riqueza de experiência de democracia cultural à mera estratégia política. É à análise do momento atual da política do MinC que iremos nos deter na parte que segue.

\section{EM BUSCA DA CONFORMAÇÃO DA POLÍTICA CULTURAL NO GOVERNO TEMER}

Se na breve passagem de Calero ocorreu a desocupação dos prédios do Ministério, sinalizando um certo arrefecimento do movimento, isso não significa a complacência de parte considerável dos agentes culturais com a gestão do MinC, em especial após a saída de Calero, que era visto como alguém do campo ${ }^{2}$, e a nomeação de Roberto Freire, uma indicação política do PPS $^{3}$.

O atual ministro Sérgio Sá Leitão, por sua vez, vem de uma trajetória baseada no projeto de política cultural inaugurado com Gilberto Gil. Jornalista de formação e profissão, Leitão assumiu, em maio de 2003, a Representação Regional do MinC no Rio de Janeiro. No mesmo ano tornou-se chefe-de-gabinete do Ministro. Nesse cargo, Leitão é constantemente chamado a falar na imprensa quando 
o assunto se refere às leis de incentivo ou temas relativos à economia da cultura.

Em 2004 foi nomeado secretário de Políticas Culturais do MinC. Responsável por conduzir o debate sobre economia criativa, defende que "[...] crescimento das pequenas e médias empresas culturais e o aumento da exportação de bens e serviços nessa área são vitais para o desenvolvimento de países emergentes que, como o Brasil, apresentam evidente vocação para esse setor." (BERGEL, 2005). Em abril de 2006, Leitão tornou-se assessor especial da presidência do Banco Nacional de Desenvolvimento Econômico e, em outubro de 2007, foi nomeado para a assessoria da presidência da Agência Nacional do Cinema (Ancine).

Em 2009 foi nomeado presidente da RioFilme, ligada à prefeitura do Rio de Janeiro. Leitão defendeu que a instituição se tornasse autossustentável, o que significou o reposicionamento da empresa e o investimento em filmes com potencial mercadológico. Isto fez com que, na sua avaliação, a RioFilme saísse da mais absoluta irrelevância e se tornasse líder em incentivo ao cinema no Rio de Janeiro. (ARANTES, 2013). Sá anunciou, em 2010, que até 2014, a empresa deverá investir $\mathrm{R} \$ 90$ milhões na área, dos quais $\mathrm{R} \$ 40$ milhões viriam da Prefeitura e o restante seria de receita própria e em parcerias com a iniciativa privada. (RIOFILMES..., 2010a).

Leitão defendeu ainda a produção de continuações de sucessos de bilheteria, ou de blockbusters (pelo menos oito produções nesse modelo começariam a filmar a partir de 2012). Para o gesto, "[...] esse boom é um sintoma de que o cinema brasileiro está finalmente deixando de ser apenas um 'cinema de diretor' para se tornar também um 'cinema de produtor." (QUEIRÓS, 2011). A RioFilmes, inclusive, seria coprodutora e codistribuidora de pelo menos dois desses projetos (De Pernas Pro Ar 2 e Muita Calma Nessa Hora 2) posto que, na sua concepção, o objetivo de investimentos de verbas públicas em filmes seria gerar lucro. (QUEIRÓS, 2011).

No entanto, essa política sofreu oposição por parte dos realizadores autorais, ou seja, que não produzem visando primordialmente o mercado. Os agentes do setor do audiovisual reuniram-se em um movimento intitulado Rio: Mais Cinema, Menos Cenário que se contrapôs à opção da empresa estatal em investir apenas em filmes lucrativos. A cineasta Julia Murat, integrante do movimento, denunciou que entre 2009 e 2014, 30\% do investimento foram desti- 
nados para apenas dez produtoras. Os $70 \%$ restantes foram divididos entre outras 147. Para Murat, essa concentração de dinheiro público seria uma "política de Estado equivocada." (RIOFILMES..., 2010b).

Em novembro de 2012, Sá assumiu a Secretaria de Cultura do município do Rio de Janeiro, acumulando com a presidência da RioFilme. Conforme anunciou na imprensa, sua atuação seria centrada em três eixos: a valorização da zona portuária como região estratégica, o investimento na economia criativa e o fomento à criação e à produção cultural, expandindo o programa de editais. Como modelo de sua futura gestão, recorre à experiência de Gil no MinC, da qual foi partícipe, como visto: "A filosofia de atuação, a visão do que é cultura, os programas e as ações. Pretendo implementar no Rio um projeto como o Cultura Viva, dos Pontos de Cultura, em grande escala." (EX..., 2012).

Em janeiro de 2015 Leitão deixou o comando da Secretaria de Cultura e da RioFilmes. Segundo anunciou na imprensa, tratava-se de decisão pessoal, motivada pelo desejo de trabalhar na iniciativa privada depois de 12 anos na administração pública. (SECRETÁRIO..., 2015). Contudo, continuou sendo um agente bastante ouvido pela imprensa, em especial quando se tratava de questões relativas à economia do audiovisual.

Não é de estranhar que, com essa trajetória ligada ao MinC e à gestão municipal de cultura de uma cidade administrada pelo PMDB, Leitão apareça como um dos possíveis nomes a assumir a anunciada Secretaria de Cultura, que deveria substituir o MinC, ainda no governo interino de Temer.

No período em que está atuando como produtor no setor do audiovisual, Leitão escreve um artigo na Folha de São Paulo em defesa da Lei Rouanet, naquele momento alvo de investigação da Polícia Federal intitulada Operação Boca Livre. A seu favor, O argumenta que aquele instrumento de renúncia fiscal seria "[...] um dos instrumentos pelos quais o governo federal estimula o desenvolvimento da indústria criativa", setor que "[...] apresenta elevado impacto social e econômico, contribuindo decisivamente para a geração de emprego e renda, para a qualificação do capital humano e para a formação da identidade da sociedade brasileira." (LEITÃO, 2016b). 
Na gestão de Freire no MinC, Leitão foi convidado para assumir um dos quatro cargos da diretoria da Ancine, órgão do qual foi assessor, como visto. A imprensa, afirma que pretende atuar em três linhas: desburocratização, transparência e mediação. Em relação à última, defende que a agência atue como mediadora dos aspectos regulatórios e não como parte, pois não cabe a ela "[...] ter uma visão sobre como o mercado deve se organizar." (MENON, 2017). Todavia, o ministro interino da Cultura, o cineasta João Batista de Andrade, indicou a também cineasta Débora Ivanov, que teve o apoio de nomes importantes do setor, como Walter Salles, Fernando Meirelles, Bruno Barreto, Luiz Carlos Barreto, Rodrigo Santoro, Bruna Lombardi, Paulo Betti, entre outros, o que descontentou a Presidência da República, defensora do nome de Leitão.

O atrito, bem como o anúncio do corte de $43 \%$ do Orçamento do MinC, levou Andrade a pedir demissão do cargo. Na sua avaliação, o ambiente não era propício a uma boa política cultural e, com o corte orçamentário, o ministério teria ficado inviável. (BERGAMO; DIAS; MARTÍ, 2017).

Avaliado pelo governo como alguém com "[...] ampla e reconhecida experiência na área cultural”, "[...] alguém que conhece a fundo as manifestações culturais do nosso povo.” (AQUINO, 2017), Temer indica Leitão para assumir o MinC. Na realidade, havia uma pressão para que a nomeação fosse política, mas diante do receio de mais reações contrárias do campo cultural, optou-se por uma indicação técnica e com trânsito no meio político. Ou seja, tratava-se de um agente que reunia a capacidade de defesa do governo a partir do lugar institucional da cultura e a de propor uma política cultural adequada à política governamental.

Em adequação ao posicionamento esperado, o ministro, logo após assumir o cargo, se propôs a criar consensos entre os agentes do campo ao se colocar como ministro de toda a cultura brasileira e a favor do bom senso e da contemporaneidade. Ao mesmo tempo, em seu discurso de posse, defendeu as reformas do governo ao afirmar que "[...] precisamos sair logo da crise, em todas as áreas [...] E isso se faz com reformas estruturais, não com a fácil omissão". Os resultados destas reformas já seriam visíveis, pois "[...] estamos começando a sair da maior recessão de nossa história." (URIBE; FRANCO, 2017). 
A sua proposta é reconstruir o Ministério, reduzindo custos e aumentando receitas por meio do choque de gestão e da desburocratização (URIBE; FRANCO, 2017), valores que já tinha mobilizado em sua passagem pela gestão pública. Para Leitão (2016a), a pasta não diferiria do resto do Estado brasileiro, hipertrofiado e sem a devida qualidade nos serviços prestados aos cidadãos. Então, seria preciso avaliar se o Ministério não estaria, historicamente, se dedicando a fazer coisas que "[...] não sejam prioritárias do ponto de vista da sociedade e da cultura brasileira." (FRANCO; URIBE, 2017).

Antes mesmo de ser ministro, quando da recriação do MinC por Temer, Leitão (2016a) escreveu um artigo para a Folha de São Paulo onde avaliou a medida "[...] necessária para diminuir a temperatura da crise que se instalou", apesar de não representar "[...] em si um fato necessariamente positivo ou negativo", pois não se trata de uma questão institucional e sim "[...] apontar claramente, por meio de ações, qual é o papel da cultura para a gestão Temer". E para isso seria necessário retomar o ideário de Gil no MinC e "[...] levar em conta a dimensão simbólica, econômica e cidadã". Assim, a "[...] cultura pode ser um antídoto contra a recessão, por sua capacidade de gerar renda, emprego, inclusão e felicidade.” (LEITÃO, 2016a).

Como ministro, sua definição do papel da cultura está no foco sobre o vetor econômico, o que se ajusta tanto à sua trajetória, quanto ao ideário do governo. O plano de ações, que o ministro apresentou ao presidente Temer, se estrutura em cinco pilares. O primeiro é o choque de gestão em busca da eficiência; o segundo é um conjunto de reformas, que inclui a Lei Rouanet, mas também os modelos de gestão dos equipamentos culturais sob responsabilidade do governo federal, uma vez que o padrão de gerenciamento integralmente estatal não seria mais viável, o que exigiria "[...] ceder a administração desses espaços culturais a organizações sociais e à iniciativa privada" (BRASIL, 2018); o terceiro é a entrega de programas que estão sendo executados pelo Ministério e por suas vinculadas; o quarto pilar é a construção do plano de diretrizes e metas do MinC para a área cultural, que deverá orientar, inclusive, as futuras gestões do Ministério; por fim, o quinto pilar é a economia da cultura, "[...] uma bela contribuição nesse momento em que o Brasil começa a sair da crise." (BRASIL, 2018).

Em entrevista à Folha de São Paulo, Leitão esclarece que a transformação da Secretaria de Economia Criativa, criada no início 
da gestão Ana de Hollanda, em Secretaria da Economia da Cultura, na passagem de Calero pelo MinC, é apenas uma mudança de cunho acadêmico, mas que o essencial permanecia: o entendimento que as atividades culturais e criativas têm valor simbólico e econômico. A Secretaria da Economia Criativa teria falhado na elaboração e implementação de sua política, ao não "[...] sensibilizar o conjunto da sociedade, os políticos e o governo" e em não "formular um conjunto de políticas mais eficientes." (MUNIZ, 2017).

Haveria, portanto, urgência em desenvolver maneiras de aproveitar melhor a vocação do país para as atividades culturais-criativas por seu peso econômico e seu potencial de crescimento. Para tanto, o poder público deveria estimular esses setores por meio de instrumentos de crédito de modo a aumentar o investimento privado e sua participação no Produto Interno Bruto (PIB). Nesse contexto, a meta do MinC até o fim do governo (2018) seria “"...] deixar o ministério dotado de um conjunto de diretrizes, políticas e ações voltadas à economia criativa". O que requer articulação com o Ministério da Indústria, do Comércio Exterior e Serviços (MDIC), o B anco Nacional de Desenvolvimento Econômico e Social (BNDES) e o Sistema S, além de definir, junto com o IBGE, a conta satélite de cultura, que vem sendo discutida desde dezembro de 2010, quando se formalizou o convênio interinstitucional entre os Ministérios da Cultura, da Fazenda e do Planejamento, Orçamento e Gestão. (LINS, 2015; MUNIZ, 2017).

Em artigo publicado na Folha de São Paulo, onde volta a defender a Lei Rouanet, Leitão retoma os mesmos argumentos do artigo anterior onde ressalta o papel deste instrumento de incentivo como principal mecanismo de fomento à cultura no Brasil e que traz um "[...] equilíbrio saudável entre mercado e Estado" (LEITÃO, 2017b). Em artigo posterior, o ministro reafirma a necessidade "[...] de transformar o modo como a cultura, a política cultural e a Lei Federal de Incentivo à Cultura são encaradas no Brasil.” (LEITÃO, 2017a). Isso implica o entendimento da política cultural governamental como um "[...] cardápio de ações de promoção de desenvolvimento econômico, com o objetivo de estimular o crescimento de um setor que contribui imensamente ao país". (LEITÃO, 2017a). Nessa lógica, a Lei Rouanet seria um "[...] instrumento de política econômica, visando ampliar o financiamento de projetos culturais realizados por empresas pequenas, médias e grandes de todas as regiões do país e de todos os segmentos da economia criativa" (LEI- 
TÃO, 2017a), cujos benefícios não seriam apenas dos agentes do campo cultural, mas de toda a sociedade.

Mais uma vez recorrendo às ideias basilares da gestão Gil, Leitão (2017b) afirma “[...] a cultura como setor estratégico da economia, sem esquecer a dimensão simbólica e o impacto na constituição da identidade nacional, na formação do capital humano e no estímulo à diversidade e à tolerância". A Rouanet, portanto, não seria apenas um meio de promoção do crescimento do setor, mas uma "[...] maneira vencedora de promover o desenvolvimento do país e o bem-estar da sociedade." (LEITÃO, 2017a).

\section{CONCLUSÃO}

Toda análise sobre as políticas públicas do governo Temer tem que levar em conta o momento de crise generalizada (política, econômica, social e cultural) que o país vive e a instabilidade daí decorrente, o que limita o alcance de suas conclusões e muito mais ainda de suas previsões. Contudo, a partir do referencial teórico mobilizado e dos indícios empíricos recolhidos, é possível dizer que as duas hipóteses levantadas na introdução do artigo são pertinentes.

No que diz respeito à primeira hipótese, diante de um campo cultural politizado e de agentes político-culturais mobilizados, o governo Temer, ainda no período da interinidade, não só desistiu de extinguir o MinC, como nomeou um ministro com ligações com o campo. Quando, com a saída de Calero, é nomeado Freire, uma indicação política, este sofre forte oposição por parte dos agentes. A sua demissão do cargo configurou-se como uma janela para que o Ministério voltasse a ser comandado por um nome respaldado pelo setor, apesar da forte pressão dos partidos da base do governo pela indicação política. A nomeação de Leitão, como revela a sua trajetória, atendeu aos quesitos político-cultural (agente oriundo do campo) e político-partidário (ligações com o PMDB), reunindo, assim, a capacidade de fazer tanto a defesa do governo, quanto a conformação da política cultural.

Quanto à segunda hipótese, por conta da relação de Leitão com a gestão Gil, constantemente evocada em suas falas públicas gestão que teve forte aprovação por parte considerável da sociedade civil -, o ministro não rompe com os aspectos básicos daquela gestão, mas foca em uma de suas dimensões, a econômica, de acordo, mais uma vez, com a sua trajetória, mas também em conformação 
com a política liberal do governo vigente, voltada para os valores do mercado. Valores estes que não eram de todo hostilizados por setores do campo cultural, como demonstra o posicionamento de determinados agentes ainda durante o Fica MinC, que defenderam o diálogo com o Ministério recém-criado por conta do papel econômico da cultura e dos instrumentos de incentivo fiscal. Compreende-se, assim, que a política do ministro se volte para a economia criativa e/ou da cultura e para o fortalecimento da Lei Rouanet.

\section{REFERÊNCIAS}

AQUINO, Y. Jornalista Sá Leitão toma posse no Ministério da Cultura. Agência Brasil, Brasília, DF, jul. 2017. Disponível em:<http:// agenciabrasil.ebc.com.br/cultura/noticia/2017-07/jornalista-sergiosa-leitao-toma-posse-no-ministerio-da-cultura $>$. Acesso em: 13 dez. 2017.

BRASIL. Ministério da Cultura. Ministro apresenta plano de ações do MinC ao presidente Temer. Brasília, DF, ago. 2018. Disponível em: $<$ http://www.cultura.gov.br/ noticias-destaques/-/asset_publisher/OiKX3X1R9iTn/ content/ministro-apresenta-plano-de-acoes-do-mincao-presidente-temer $/ 10883$ ? redirect=http $\% 3 \mathrm{~A} \% 2 \mathrm{~F} \% 2$ Fwww.cultura.gov.br\%2Fnoticias-destaques\%3Fp_p_ id\%3D101_INSTANCE_OiKX3x1R9iTn\%26p_p_ lifecycle\%3 D0\%26p_p_state\%3Dnormal\%26 p_p mode $\% 3$ Dview\%26p_p_col_id\%3Dcolumn-1\%26 p_p col_count\%3D1\%26_101_INSTANCE_OiKX3 x1R9iTn advancedSearch\%3Dfalse\%26_101_INSTANCE OiKX3xlR9iTn_keywords\%3 D\%26_101_INSTANCE OiKX3x1R9iTn_delta\%3D15\%26p_r_p_ 564233524 resetCur\%3Dfalse\%26_101_INST $\bar{A} \bar{N} \mathrm{C} \overline{\mathrm{E}}$ OiKX3x1R9iTn_cur\%3 $20 \% 26$ - 101 INSTANCE OiKX3x1R9iTn_andOperator\%3 Dtrue $>$. Acesso em: 13 dez. 2017.

ARANTES, S. Projeto de agência de fomento faz aflorar divergências no cinema paulista. Folha de São Paulo, São Paulo, maio 2013. Disponível em http://www1.folha.uol.com.br/ ilustrada/2013/05/1286236-projeto-de-agencia-de-fomento-faz-aflorardivergencias-no-cinema-paulista.shtml. Acesso em 13.dez.2017

BARBALHO, A. "Acho que o que eu peguei foi uma coisa meio fora do normal”: mobilização e crise na gestão Ana de Hollanda. In: 
CALABRE, L.; LIMA, D. R. (Org.). Políticas culturais: conjunturas e territorialidades. Rio de Janeiro: Casa de Rui Barbosa, 2017a. p. 3348.

Em tempos de crise: o MinC e a politização do campo

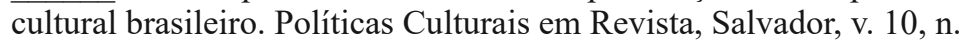
1, p. 23-46, 2017b.

; RUBIM, A. Política cultural y cultura política en el Brasil contemporáneo. In: ALCAYAGA, M. R. (Org.). La gestión cultural en 3D: debates, desafíos y disyuntivas. Cidade do México: Fondo de Cultura Económica, 2015. p. 261-282.

BERGAMO, M.; DIAS, M.; MARTÍ, S. Ministro da Cultura pede demissão e diz que a pasta se tornou 'inviável'. Folha de São Paulo, São Paulo, jun. 2017. Disponível em:<http://www1.folha.uol.com.br/ ilustrada/2017/06/1893432-ministro-da-cultura-pede-demissao-e-dizque-a-pasta-se-tornou-inviavel.shtml>. Acesso em: 13 dez. 2017.

BERGEL, M. Economia Criativa: setor, que movimenta US\$ 1,3 tri ao ano, terá centro de estudos em Salvador. Holofotes realçam indústria cultural. Folha de São Paulo, São Paulo, nov. 2005. Disponível em:<http://www1.folha.uol.com.br/fsp/negocios/cn2711200501.htm>. Acesso em: 13 dez. 2017. 1992.

. A economia das trocas simbólicas. São Paulo: Perspectiva,

. O poder simbólico. Lisboa: Difel, 1989. Seuil, 2012.

. Sur l'État: Cours au Collège de France - 1989-1992. Paris:

BRAGA, I. Temer recua e decide recriar o Ministério da Cultura, com Marcelo Calero. O Globo, Rio de Janeiro, maio 2016. Disponível em: $<$ http://oglobo.globo.com/cultura/temer-recua-decide-recriarministerio-da-cultura-com-marcelo-calero-19351863>. Acesso em: 29.jun.2016.

CASTELLO, J. Cultura. In: LAMOUNIER, B.; FIGUEIREDO, R. (Org). A era FHC: um balanço. São Paulo: Cultura, 2002. p. 627-656.

CRUZ, V.; COLON, L.; BRISOLLA, F. Temer decide recriar Ministério da Cultura, anuncia Mendonça Filho. Folha de São Paulo, São Paulo, maio 2016. Disponível em:<http://www1.folha.uol.com.br/ ilustrada/2016/05/1773764-temer-decide-recriar-ministerio-da-culturaanuncia-mendonca-filho.shtml>. Acesso em 23.jun.2016. 
DAGNINO, E. Os movimentos sociais e a emergência de uma nova cidadania. In: . Anos 90: política e sociedade no Brasil. São Paulo: Brasiliense, 1994. p. 103-118.

Políticas culturais, democracia e projeto neoliberal. Revista Rio de Janeiro, Rio de Janeiro, n. 15, p. 45-66, 2005.

States, Markets and Society: new relationships for a new development era. IDS Bulletin, [S. 1.], v. 47, n. 2, p. 157-168, nov. 2016.

EX-presidente da Riofilme é o novo secretário municipal de cultura do Rio. Folha de São Paulo, São Paulo, nov. 2012. Disponível em: $<$ http:// www1.folha.uol.com.br/ilustrada/1179259-ex-presidente-da-riofilmee-o-novo-secretario-municipal-de-cultura-do-rio.shtml>. Acesso em: 13 dez. 2017.

FRANCO, L. Restituição do MinC e diálogo com novo ministro dividem classe artística. Folha de São Paulo, São Paulo,,maio 2016. Disponível em: $<$ http://www1.folha.uol.com.br/ ilustrada/2016/05/1774682-restituicao-do-ministerio-da-culturadivide-classe-artistica.shtml $>$. Acesso em 23.jun.2016

; URIBE, G. Novo ministro quer mudar Rouanet e diz que pode encerrar programas. Folha de São Paulo, São Paulo, jul. 2017. Disponível em:<http://www1.folha.uol.com.br/ ilustrada/2017/07/1904637-novo-ministro-quer-mudar-rouanet-e-dizque-pode-encerrar-programas.shtml>. Acesso em: 13 dez. 2017.

FUNDAÇÃO ULYSSES GUIMARÃES. A travessia social. Brasília, DF, 2016.

. Ponte para o futuro. Brasília, DF, 2015.

LACERDA, A.; MARQUES, C. de C.; ROCHA, S. C. Programa Cultura Viva: uma nova política do Ministério da Cultura. In: RUBIM, A. (org.). Políticas culturais no governo Lula. Salvador: UFBA, 2010. p. 133-154.

LEITÃO, S. Há distorções, mas o Brasil é melhor com a lei do que sem ela. Folha de São Paulo, São Paulo, 29 jun. 2016a. Opinião. Disponível em: $<$ http://www1.folha.uol.com.br/ ilustrada/2016/06/1786765-ha-distorcoes-mas-o-brasil-e-melhor-coma-lei-do-que-sem-ela.shtml>. Acesso em: 22 nov. 2017.

. Menos discurso, mais ação. Folha de São Paulo, São Paulo, 24 maio 2016b. Opinião. Disponível em: $<$ http://www1.folha.uol. 
com.br/opiniao/2016/05/1774354-menos-discurso-mais-acao.shtml>. Acesso em: 22 nov. 2017.

. Não há risco de censura ou análise de conteúdo na Lei Rouanet. Folha de São Paulo, São Paulo, 16 out. 2017a. Opinião. Disponível em: $<$ http://www1.folha.uol.com.br/ ilustrada/2017/10/1927333-nao-ha-risco-de-censura-ou-analise-deconteudo-na-lei-rouanet.shtml>. Acesso em: 12 dez 2017.

. Um novo olhar sobre a cultura. Folha de São Paulo, São $\overline{\text { Paulo, } 7}$ dez. 2017b. Opinião. Disponível em:<http://www1.folha. uol.com.br/opiniao/2017/12/1941270-um-novo-olhar-sobre-a-cultura. shtml>. Acesso em: 12 dez. 2017.

LINS, C. Levantamento da ação institucional entre o MinC e o IBGE: desde as gestões Gil/Juca. Políticas Culturais em Revista, Salvador, v. 2, n. 8, p. 1-27, 2015.

MARIETA Severo, Patrícia Pillar e artistas do Ocupa MinC prometem manter atos contra Temer. O Globo, Rio de Janeiro, maio 2016. Disponível em: $<$ http://oglobo.globo.com/cultura/marieta-severopatricia-pillar-artistas-do-ocupa-minc-prometem-manter-atos-contratemer-19360319\#ixzz4CzZ6eNp3>. Acesso em: 29 jun. 2016.

MARTINS, H. F. O plano Gestão Pública para um Brasil de Todos:sḶ:em busca de uma nova geração de transformações da gestão pública. In: CONGRESO INTERNACIONAL DEL CLAD SOBRE LA REFORMA DEL ESTADO Y DE LA ADMINISTRACIÓN PÚBLICA, 8., 2003, Panamá. Anais... Panamá: CLAD, 2003. Disponível em: $<$ https://www.google.com.br/webhp?sourceid=chromeinstant $\&$ ion $=1 \&$ espv $=2 \&$ ie $=$ UTF- $8 \# q=022$ gest $\% \mathrm{C} 3 \% \mathrm{~A} 3 \mathrm{o}+\mathrm{p} \% \mathrm{C} 3 \% \mathrm{~B}$ Ablica+para+um+brasil+de+todos\%22\&*>. Acesso em: 15.mar.2017.

MCADAM, D.; TARROW, S.; TILLY, C. Para mapear o confronto político. Lua Nova, São Paulo, 76, p. 11-48, 2009.

MELO, M. A. Crisis and integrity in Brazil. Journal of Democracy, [S. 1.], v. 27, abr. 2016.

MENDES, H.M. O palco de Collor: a precarização da política cultural no governo de Fernando Collor. Rio de Janeiro: Multifoco, 2015.

MENON, I. Sérgio Sá Leitão é aprovado em sabatina e será novo diretor da Ancine. Folha de São Paulo, São Paulo, abr. 2017. Disponível em:<http://www1.folha.uol.com.br/ ilustrada/2017/04/1875008-sergio-sa-leitao-e-aprovado-em-sabatinae-sera-novo-diretor-da-ancine.shtml>. Acesso em: 13 dez. 2017. 
MUNIZ, C. Desenvolver a economia criativa será prioridade, diz ministro da Cultura. Folha de São Paulo, São Paulo, ago. 2017. Mercado. Disponível em: $<$ http://www1.folha.uol.com.br/ mercado/2017/08/1912651-desenvolver-a-economia-criativa-seraprioridade-diz-ministro-da-cultura.shtml>. Acesso em: 13 dez. 2017.

PASQUINO, G. Crise. In: BOBBIO, N.; MATTEUCCI, N.; PASQUINO, G. (Org.). Dicionário de Política. Brasília, DF: UNB, 2000. v. I.

QUEIRÓS, A. Rebobine, por favor: após o sucesso de 'Tropa 2', cinema nacional aposta na continuação de blockbusters. São Paulo, São Paulo, dez. 2011. Disponível em: $<$ http://www1.folha.uol.com.br/ fsp/ilustrada/17436-rebobine-por-favor.shtml>. Acesso em: 22 nov. 2017.

REIS, P. Plano Nacional de Cultura: estratégias e ações para dez anos. In: RUBIM, A. (org.). Políticas culturais no governo Lula. Salvador: UFBA, 2010. p. 49-66.

RIOFILME quer se tornar empresa lucrativa. Folha de São Paulo, São Paulo, set. 2010. Disponível em:<http://www1.folha.uol.com.br/ ilustrada/2010/09/806213-riofilme-quer-se-tornar-empresa-lucrativa. shtml>. Acesso em: 12 dez. 2017.

RIOFILME reage a protestos e anuncia editais que somam R\$ 10 milhões. Folha de São Paulo, São Paulo, set. 2010. Disponível em:<http://www1.folha.uol.com.br/ilustrada/2014/10/1525447riofilme-reage-a-protestos-e-anuncia-editais-que-somam-r-10-milhoes. shtml>. Acesso em: 13 dez. 2017.

RUBIM, A. (Org). Políticas Culturais no Governo Lula. Salvador: EDUFBA, 2010.

. As Políticas Culturais e o Governo Lula. São Paulo: Fundação Perseu Abramo, 2011

SECRETÁRIO de Cultura do Rio deixa seu cargo no governo e na RioFilme. Folha de São Paulo, São Paulo, 2015. Disponível em:<http://www1.folha.uol.com.br/ilustrada/2015/01/1574921secretario-de-cultura-do-rio-deixa-seu-cargo-no-governo-e-nariofilme.shtml>. Acesso em: 13 dez. 2017.

SOTO, C. et al. Políticas públicas de cultura: os mecanismos de participação social. In: RUBIM, A. (org.). Políticas culturais no governo Lula. Salvador: UFBA, 2010. p. 25-48. 
URIBE, G; FRANCO, L. Novo ministro da Cultura critica 'clima de radicalização' e pede união. Folha de São Paulo, São Paulo, jul. 2017. Disponível em: <http://www1.folha.uol.com.br/ ilustrada/2017/07/1904138-novo-ministro-da-cultura-toma-possedefendendo-governo-temer.shtml>. Acesso em: 13 dez. 2017.

\section{Notas:}

Para Bourdieu (2012), em termos epistemológicos, ou seja, da compreensão do funcionamento do Estado, os momentos de crises são momentos propícios, como os de gênese, pois as imposições simbólicas se tornam evidentes. No caso dos segundos, porque ainda estão se constituindo, no caso dos primeiros, porque são reveladas pelos heterodoxos que as colocam em xeque.

2 Calero é advogado e diplomata de carreira. Concorreu a deputado federal pelo PSDB em 2010. Foi presidente do Comitê "Rio 450", criado pela prefeitura para organizar a celebração do $450^{\circ}$ aniversário da cidade, cargo que deixou para assumir a Secretaria de Cultura do município em 2015. =

3 Freire é advogado e deputado pelo PPS, partido do qual foi um dos fundadores e é seu atual presidente. 